\title{
Effect of Heat Treatments on the Mechanical Properties of Welded Joints of Alloy Steel by Arc Welding
}

\author{
Hamid M. Mahan \\ Baquba Technical Institute, Middle Technical University (MTU) \\ hamid19812052016@gmail.com \\ hamid1980@mtu.edu.iq
}

\begin{abstract}
This research deals with influence of the heat treatment on welded joints using the shielded metal arc welding (SMAW) on three types of steel with different carbon ratios under constant conditions such as the thickness of metal $20 \mathrm{~mm}$, welding current 120A, voltage $80 \mathrm{~V}$, Diameter $15 \mathrm{~mm}$ and angle 60 degree. Mechanical tests were carried out to include tensile, bending, micro hardness and microstructure testing. The results showed that the steel with a low carbon content has the highest value of hardness after performing heat treatment in the area of welding line $370 \mathrm{HV}$. Unlike the moderate carbon- steel, the value of hardness was higher in the $310 \mathrm{HV}$, the tensile strength of steel decreased to 554Mpa when carrying out the heat treatment compared with steel containing higher carbon ratios $523 \mathrm{MPa}$. In the other side improving toughness and impact strength for welded joints on which heat treatments have been conducted after the welding process, where highest impact value was obtained in the high carbon steel $214 \mathrm{~J}$.
\end{abstract}

Keyword: Heat treatments, Mechanical properties, microstructure, welded joints.

\section{Paper History:}

(Received: 7/9/2017; Accepted: 12/2/2018)

\section{Introduction}

With the technological development in advanced industries such as oil, automotive, aviation, piping networks, metallic bridges and other important industries, the need for a high-quality welding splices has increased [1]. Many studies have shown that the welding joints are cracked when they are exposed to dynamic loads that start in the transition zones from the weld line to the Basic metal has been demonstrated through numerous tests conducted in the field of fatigue tests [2]. The shape, dimension and reinforcement amount of the welded druse in welding line affect the extent of withstand of the different welding joints (whether these joints are spherical, perpendicular or otherwise) [3]. It is noticeable that whenever the values of transition angle increases between the welding line and the base metal, the values of extent withstand increases for spherical joints treated using this method.
The mechanical methods varied to alleviate the sudden transition between the weld line and the base metal [4]. The grinding and rolling methods were used to make a smooth transition between the welding line and the base metal, and then reduce the concentration of the remaining stresses in this region [5].In the welding process, a high temperature is generated to melt the welding metal, the conditional interface between the welding metal and the welding zone is called fusion limits [6].

The temperature and cooling rate of the heat-affected area varies depending on the distance from the fusion line between the weld metal and the heat-affected area. As a result of this difference, the microstructure varies, although the chemical structure is not different [7]. Various mechanic and heat treatments are conducted on some metals that lead to reduce the stresses and distortions of the welded metals, these treatments include heating, pre-pressing, and heat treatment after the welding process [8]. These treatments reduce or remove the stresses and cracking, change the metallic properties of welded joints and to get the precise structure of the basic metal and metal fillers. The heat treatments affect (the temperature at which the metal is exposed, fixing period, the chemical composition of the metal, and cooling rate) [9].

The main objective of this research is to study the influence of heat treatments on the mechanical properties conducting on welded joints after welding process using arc welding, where three samples of steel were used with different carbon ratios in constant conditions (current, voltages, thickness of the metal). The changes that occur on the mechanical properties in the heat effect zone HAZ and the base metal have been research in this study.

\section{Experimental Work}

In this study, welding of butt joints from steel with different carbon content ratios was conducted. The chemical compositions of the sample according to standard properties is shown in table (1). Plates of steel 
with different carbon ratios were cut to parts with dimensions $(120 \times 15 \times 20) \mathrm{mm}$. Cleaning process was conducted on all the plates to remove dusts and greases. Then , preparing the welding edges of these parts using the mechanical operation on milling machine. The rinsing process was performed at angle $60^{\circ}$ and side width $(15$ $\mathrm{mm})$.The parts were properly positioned to make rinsed butt edge with single side (single-V). The dimensions of welded piece were constant for the three different metals of various carbon ratios as shown in figure (1).The welding process alloy steel with a thickness of $20 \mathrm{~mm}$ was carried out on two stages using electric arc welding and welding electrodes of type (E8013).

The first stage : The welding process was conducted using the five passes on weld of the three samples with different carbon ratios as shown in figure (2).

The second stage : Welding process was done by arc welding (SMAW) using the four passes. After welding process, heat treatments have been done for samples at a temperature of $500^{\circ} \mathrm{C}$ and the time of installation $15 \mathrm{~min}$ and then cooling inside the furnace by using the furnace as shown in figure (2). Examine process was performed for chemical compositions of the welding electrode used as shown in the table (2). The electrode with diameter 3.5 mm was used with constant of current and voltage 120 amp and 80 volts respectively.

The changes that occurs in the microscopic structure have been studied with the mechanical properties of welded joint passes. The properties of these welded joints have been evaluated . Figure (3) shows a photograph of a welded sample of steel. After the welding process for different metals, the samples were prepared to show the microstructure of the metals used in the research. The wet smoothing with water using smoothing paper of type sic at different degrees of smoothness started from 220, 320, 500, 800, and 1200 respectively, then the polishing process was done using alumina solution and specimens were etched with $2 \%$ of Nital solution to reveal the microstructural and features of welded joints for the know the phases formed in the welding zone, the heat affected zone, metal base and the layers of the welding line.

Vickers micro hardness tester was used for measuring the hardness distribution across the welded joint with a load of $500 \mathrm{~g}$ in 30 seconds The specimen for metallographic examination was sectioned to the required size from the joint comprising weld metal, HAZ (heat affected zone), and base metal regions. The tensile test samples were operated according to ASTM-E8M standard at room temperature and the samples shape with dimensions as shown in figure(4). Charpy $\mathrm{V}$ impact tests on the notch location in the WM with dimensions samples has 55 by
10 by $10 \mathrm{~mm}$ dimensions, a $45^{\circ} \mathrm{V}$ notch of $2 \mathrm{~mm}$ depth and a $0.25 \mathrm{~mm}$ root radius as shown in figure (5) and (6).

\section{Results And Discussion}

\subsection{Micro-Hardness Test}

The welding samples were examined for accurate readings of the whole weld joint starting from the welding metal, the heat-affected area, then the base metal, and on the both welding sides, at a distance of $(1 \mathrm{~mm})$ between reading and another of the three welded joints ( samples with performing heat treatments on which and samples without performing heat treatments). The microstructure of weldment (WM) and the base metal is known that it undergoes considerable changes because of the heating and cooling cycle of the welding process [8]. Where we observed that the value of hardness is greater in the heat affected zone when the percentage of carbon increases as shown in table (3)and figure (7).

The reason behind the high hardness in the welding area when using steel (STEEL 321) is due to the union of chromium with carbon constituting chromium carbide (Cr23C6) which has property of high hardness in the hardening line due to the spread of carbon from the base metal to the welding metal.

\subsection{Tensile test}

The tensile tests have been conducted on the samples (samples with performing heat treatments on which and samples without performing heat treatments). The results were good and approximate, tensile strength is increased when performing the heat treatment after the welding process of the welded joints as shown in figure (8). A higher tensile value was obtained when a heat treatment was carried out due to spread of the carbon from the base metal to the welding area except the steel which has very low carbon ratios and improvement of toughness and this occurs due to the partial degradation (decomposition) of pearlite, This rise in tensile strength after heat treatment might have been due to the fact that stored residual stresses in the weldment are relieves[9].

The bending angle is $120^{\circ}$ and no cracking was seen in the joints. The breaking occurred in the welding area of the three metals as shown in the table (4).

\subsection{Impact test}

The impact is testing determines the amount of energy absorbed by a material during fracture. The toughness tests have been conducted on the samples (samples with performing heat treatments and samples without performing heat treatments).The result the minimum 
impact energy in before heat treatment and maximum impact energy after heat treatment because The formation of ferrite arranged in the packets could make the propagation path of critical crack pass through an ferrite acicular microstructure, thereby leading to an improvement in toughness as shown in figure (9).

\subsection{Examination of the microstructure}

The microstructure of weldment (WM) and parent metal is known that it undergoes considerable changes because of the heating and cooling cycle of the welding process. as discussed in [8] to reveal the heat affected zone (HAZ) around a weld. The microstructure tests showed that the welding zone has a dendritic structure, the size of the granules is longitudinal and large because of their fusion and congelation. It is composed of the phase of the ferrite and the pearlite phase as in figure (10) and figure (11). While the heat affected zone maintains its granules within normal size, but it is exposed to granular growth especially in the areas adjacent to welding zone. The granules are smaller in size when moving away from the weld zone to give an indication of the presence of recrystallizing areas down to the base metal, whose structure is an equal axes granular as in figure (11) and figure (12).

\section{Conclusions}

After mechanical tests conducted on welded joints, deduce the following:

1- The heat treatment has a clear and significant effect on the mechanical properties of steel, where we observe the improvement of toughness .

2- The fracture in the joints occurred in the welding area . A higher tensile

value can be obtained when performing the heat treatment.

3- In welded joints of low-alloy steels, the highest hardness is achieved in the HAZ and the average value is in the Fusion zone. In high-alloy steels, the highest hardness is achieved in the fusion zone and the average value in the HAZ .

4- The highest hardness values can be obtained in the heat affect zone, then the hardness values start relatively decrease in the base metal in contrast to the steel (Steel 321), the highest hardness value is in the welding zone.

5- Heating and cooling of the welding line zone to a change in the crystalline volume of th metal and the formation of a Hard and fragile zone.

\section{Acknowledgment:}

The author is grateful to The staff of Baquba Technical Institute / Middle Technical University (MTU)

\section{References:}

[1] Hakan, A,.(2014), " Relationship between a bainitic structure and the hardness in the weld zone of the friction stir welded X80 API grade pipe-line steel " Mater Technol, 48 (1) pp. 15802949.

[2] Jeshvaghani, R .A and Mirzaei,R ,M ,(2013),"Study of welding velocity and pulse frequency on microstructure and mechanical properties of pulsed gas metal arc welded high strength low alloy steel " Materials \& Design, Vol. 51, 709-713.

[3] Salman, H. K. , Abbass M. K. and Mohammed, A. H.,( 2015), "Effect Of Shot Peening On The Mechanical Properties For Welded Joints of Aluminium Alloy" 6061 -T6, NDMRP, Vol. 2, pp. 43-56.

[4] Armentani, E. R , (2007), "The effect ofthermal properties and weld efficiency on residual stresses in welding" Journal of Achievements in Materials and Manufacturing Engineering, Vol. 20, No. 1-2, 319-322.

[5] Frost N.E., dugdale D.E, (1991), "The propagation of fatigue cracks in sheet specimens ، "Journal of Sound \& Vibration, V.69, No. 4.

[6] Boumerzoug, Z., Raouache, E., Delaunois, F. (2011)," Thermal cycle simulation of welding process in low carbon steel" Materials Science and Engineering: A, Vol. 530, 191-195,

[7] Hastuhiko. O, Tatsuya. S, Tadashi, 2007 "Weld ability of High Strength Steel" ,(HSS)Sheets for Automobiles, Nippon Steel Technical ,No.95.

[8] Razzak, M. A. (2011), "Heat Treatment and Effects of $\mathrm{Cr}$ and $\mathrm{Ni}$ in Low Alloy Steel." ,Bulletin of Materials Science, 34, 1439-1445.

[9] Roberti, R., Cornacchia, G. and Faccoli, M. (2012), "Effect of Increasing Post Weld Heat Treatment Temperature on theFracture Toughness of an ASME SA-542M Steel." Forni di Sopra (UD), Italia. 
Table 1 Chemical composition of alloy steel.

\begin{tabular}{|l|c|c|c|c|c|c|c|c|c|c|}
\hline $\begin{array}{l}\text { Element } \\
\text { wt\% }\end{array}$ & $\mathrm{Fe}$ & $\mathrm{Cu}$ & $\mathrm{P}$ & $\mathrm{S}$ & $\mathrm{Mo}$ & $\mathrm{Ni}$ & $\mathrm{Cr}$ & $\mathrm{Si}$ & $\mathrm{Mn}$ & $\mathrm{C}$ \\
\hline STEEL 20 & Rem & 0.24 & 0.03 & 0.03 & --- & 0.23 & 0.25 & $0.19-0.35$ & $0.37-0.55$ & $\begin{array}{l}0.22- \\
0.25\end{array}$ \\
\hline Steel 12KhM & Rem & 0.18 & 0.03 & 0.023 & 0.5 & 0.22 & $0.4-0.5$ & $0.18-0.24$ & 0.5 & $\begin{array}{l}0.12- \\
0.14\end{array}$ \\
\hline STEEL 321 & Rem & $0.4-1$ & 0,035 & 0.02 & 0.3 & $\begin{array}{l}9- \\
11\end{array}$ & $17-19$ & 0.8 & 2 & 0.09 \\
\hline
\end{tabular}

Table 2 Shows the chemical composition of welding electrode used

\begin{tabular}{|c|c|c|c|c|c|c|c|c|}
\hline $\begin{array}{c}\text { Elec. } \\
\text { Type }\end{array}$ & $\mathrm{c}$ & $\mathrm{Mn}$ & $\mathrm{Si}$ & $\mathrm{Cr}$ & $\mathrm{Mo}$ & $\mathrm{S}$ & $\mathrm{P}$ & $\mathrm{V}$ \\
\hline $\mathrm{E} 8013$ & 0.06 & $0.6-0.9$ & $0.2-0.4$ & $0.8-1.2$ & 0.4 & 0.025 & 0.03 & 0.12 \\
\hline $\mathrm{E} 50217$ & 0.09 & 0.7 & 0.25 & 0.90 & 0.48 & 0.018 & 0.02 & - \\
\hline
\end{tabular}

Table 3 Table showing the hardness values of samples

\begin{tabular}{|c|c|c|c|c|}
\hline $\begin{array}{l}\text { Sample } \\
\text { Type }\end{array}$ & Process & $\begin{array}{c}\text { Fusion zone WM } \\
\mathrm{HV}\left(\mathrm{KN} / \mathbf{m m}^{2}\right)\end{array}$ & $\begin{array}{l}\text { Heat effect zone } \\
\text { HAZ } \\
\text { HV }\left(\mathrm{KN} / \mathbf{m m}^{\mathbf{2}}\right)\end{array}$ & $\begin{array}{c}\text { Base metal } \\
\text { BM } \\
\mathrm{HV}\left(\mathrm{KN} / \mathbf{m m}^{2}\right)\end{array}$ \\
\hline \multirow{2}{*}{ steel 20} & $\begin{array}{l}\text { Hardness before heat } \\
\text { treatment }\end{array}$ & 200 & 220 & 210 \\
\hline & $\begin{array}{l}\text { Hardness after heat } \\
\text { Treatment } 500^{\circ} \mathrm{c}\end{array}$ & 210 & 240 & 190 \\
\hline \multirow{2}{*}{ Steel 12khm } & $\begin{array}{l}\text { Hardness before heat } \\
\text { treatment }\end{array}$ & 250 & 280 & 210 \\
\hline & $\begin{array}{l}\text { Hardness after heat } \\
\text { Treatment } 500^{\circ} \mathrm{c}\end{array}$ & 270 & 310 & 220 \\
\hline \multirow{2}{*}{ steel 321} & $\begin{array}{l}\text { Hardness before heat } \\
\text { treatment }\end{array}$ & 350 & 310 & 340 \\
\hline & $\begin{array}{l}\text { Hardness after heat } \\
\text { Treatment } 500^{\circ} \mathrm{c}\end{array}$ & 370 & 345 & 330 \\
\hline
\end{tabular}

Table 4 Mechanical properties of the parent metal and welded joints.

\begin{tabular}{|c|l|c|c|c|}
\hline \multirow{2}{*}{ Sample Type } & \multicolumn{1}{|c|}{ Heat treatment } & $\begin{array}{c}\text { Tensile strength } \\
(\mathrm{MPa})\end{array}$ & $\begin{array}{c}\text { Impact } \\
\text { energy } \\
\text { KV (J) }\end{array}$ & $\begin{array}{c}\text { Bending } \\
\text { angle } \\
(\text { Degree })\end{array}$ \\
\hline \multirow{3}{*}{ Steel 20} & before heat treatment & 416 & 205 & 119 \\
\cline { 2 - 5 } & after heat Treatment $500 \mathrm{c}^{\mathbf{o}}$ & 421 & 214 & 119 \\
\hline \multirow{3}{*}{ Steel $12 \mathrm{khm}$} & before heat treatment & 512 & 178 & 120 \\
\cline { 2 - 5 } & after heat Treatment $500 \mathrm{c}^{\mathbf{o}}$ & 523 & 181.5 & 120 \\
\hline \multirow{3}{*}{ Steel 321 } & before heat treatment & 577 & 270 & 120 \\
\cline { 2 - 5 } & after heat Treatment $600 \mathrm{c}^{\mathbf{o}}$ & 554 & 278 & 120 \\
\hline
\end{tabular}




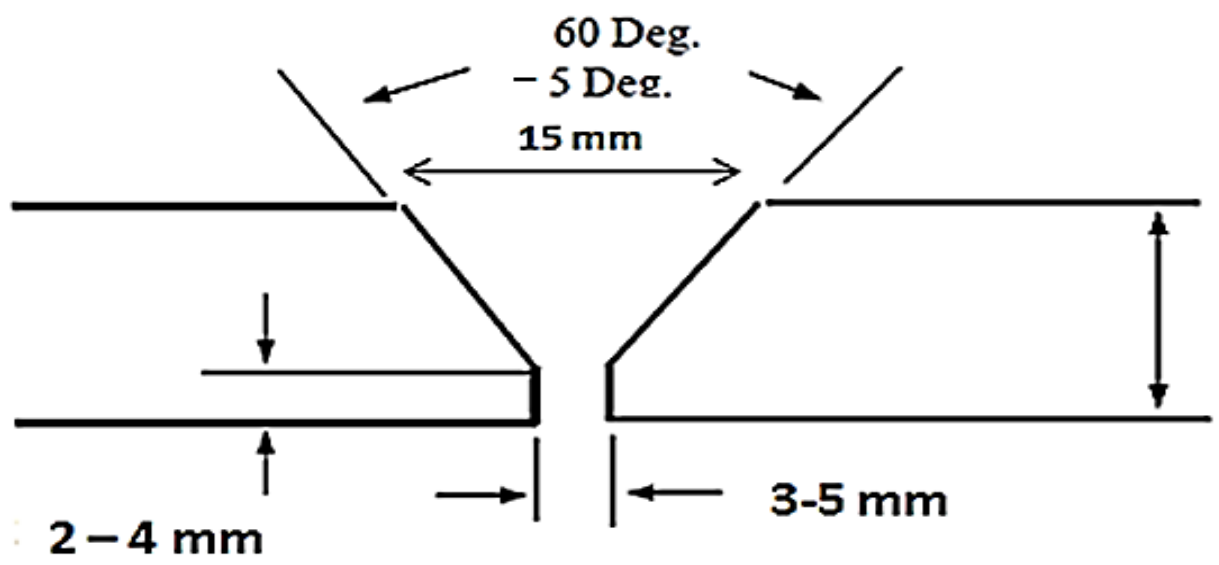

Figure 1: Shows the dimensions of the sample used in the welding process

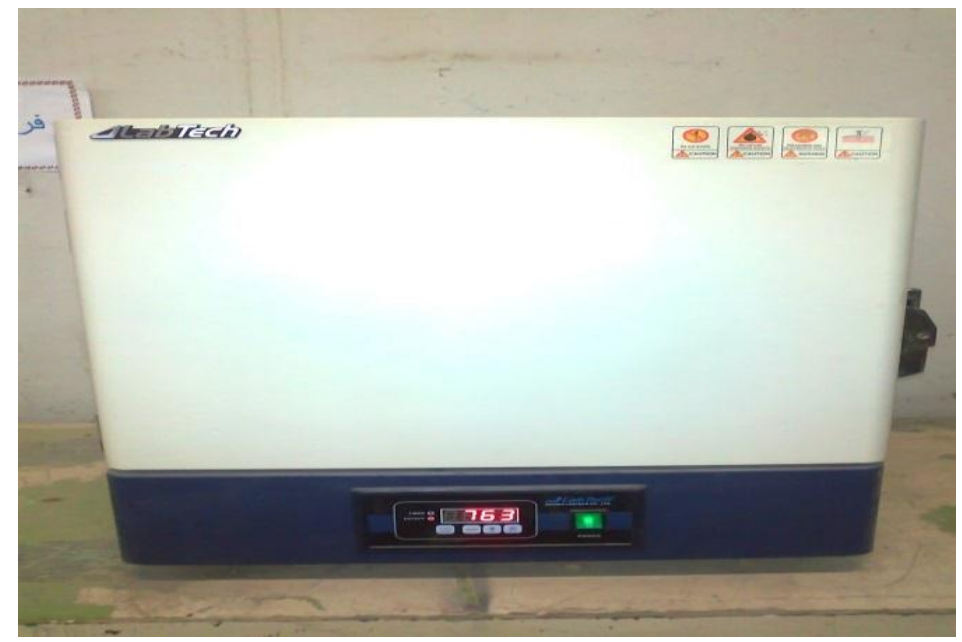

Figure 2: Furnace at $1200 \mathrm{C}^{\circ}$
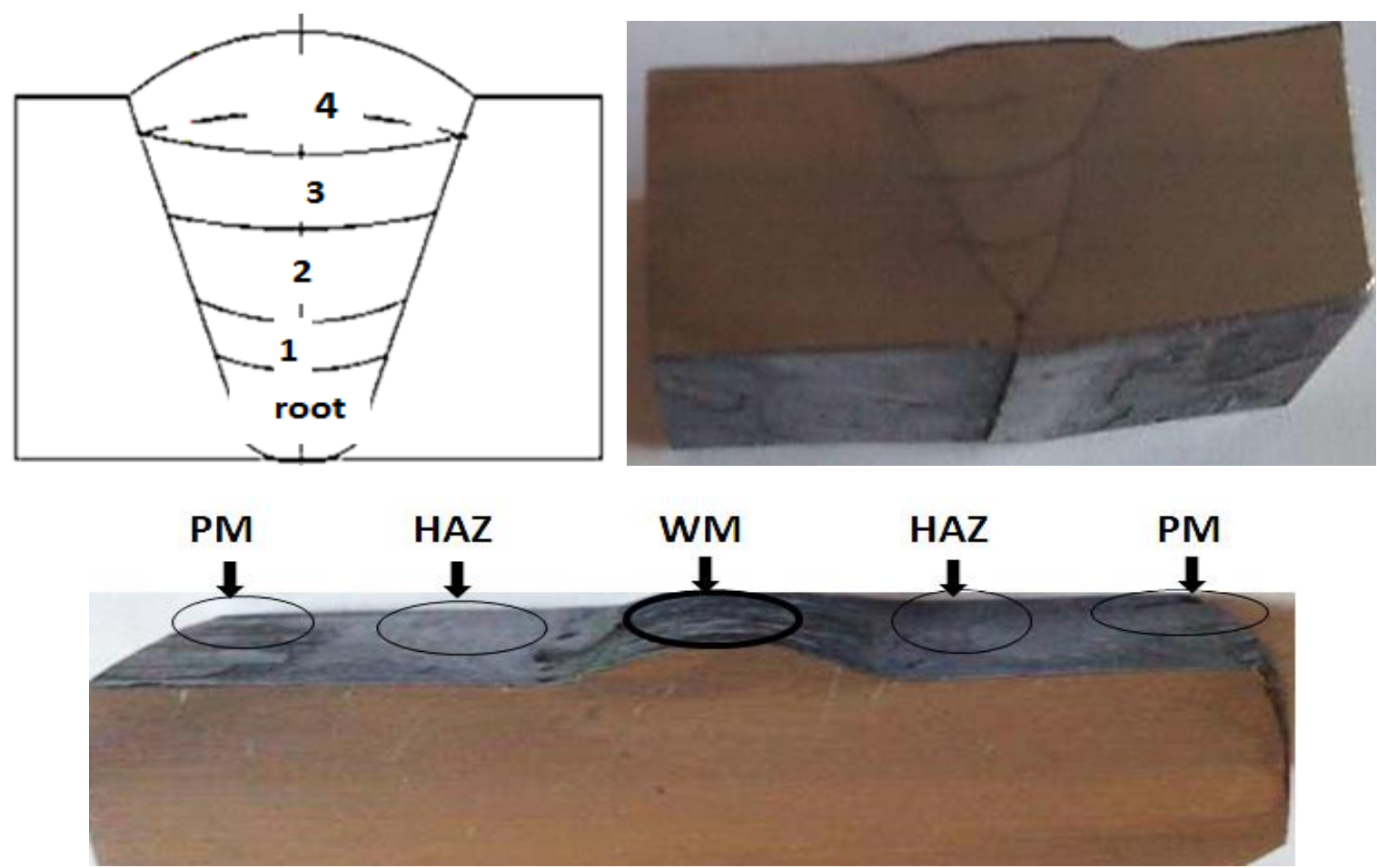

Figure 3: Shows a sample of welded steel photograph 


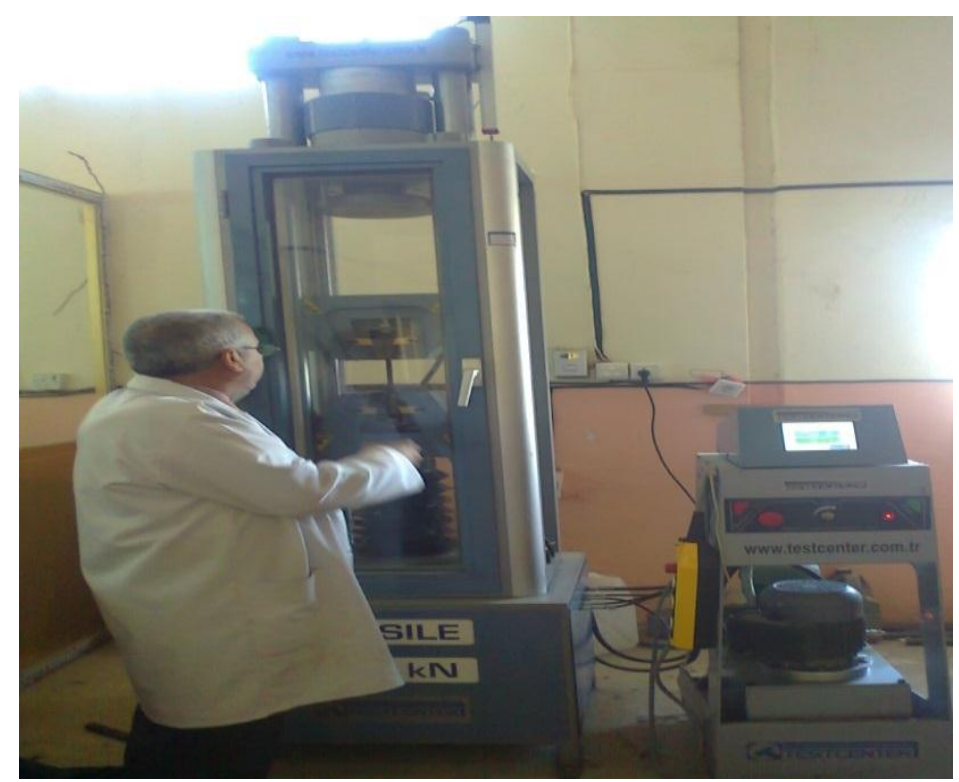

Figure 4: Tensile test machine

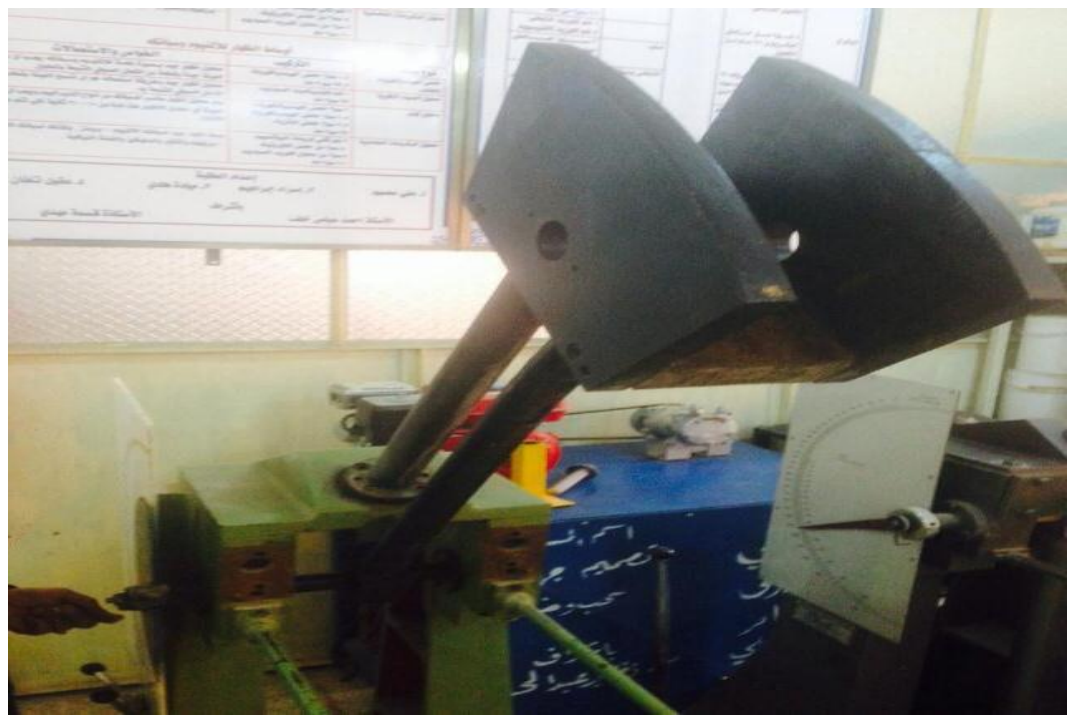

Figure 5: Impact test machine
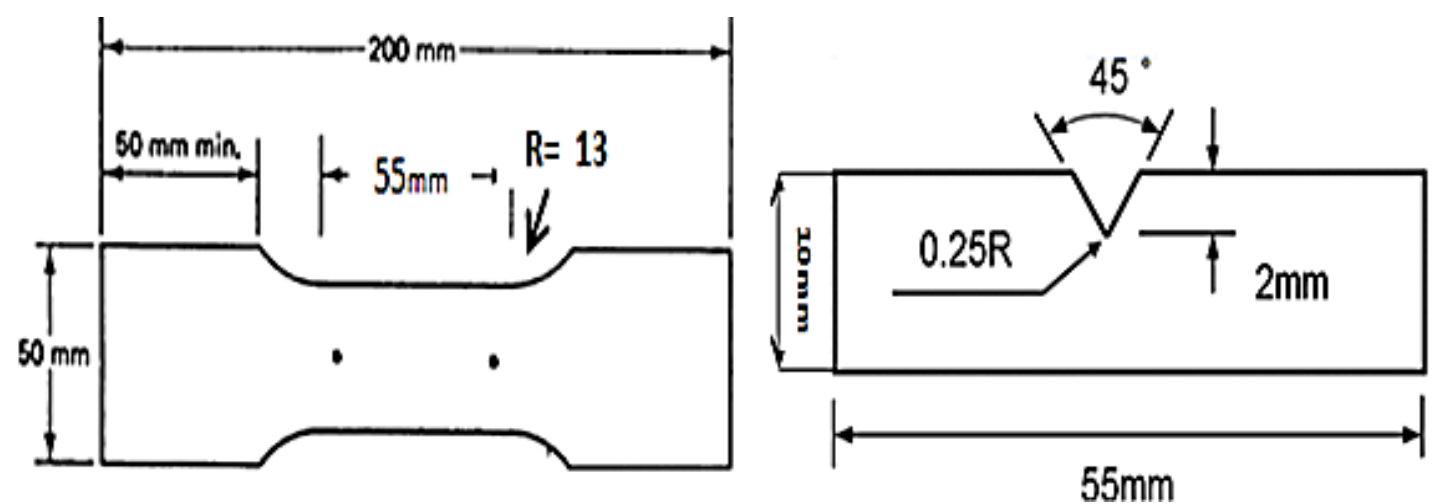

Figure 6: Test samples of tensile and impact. 

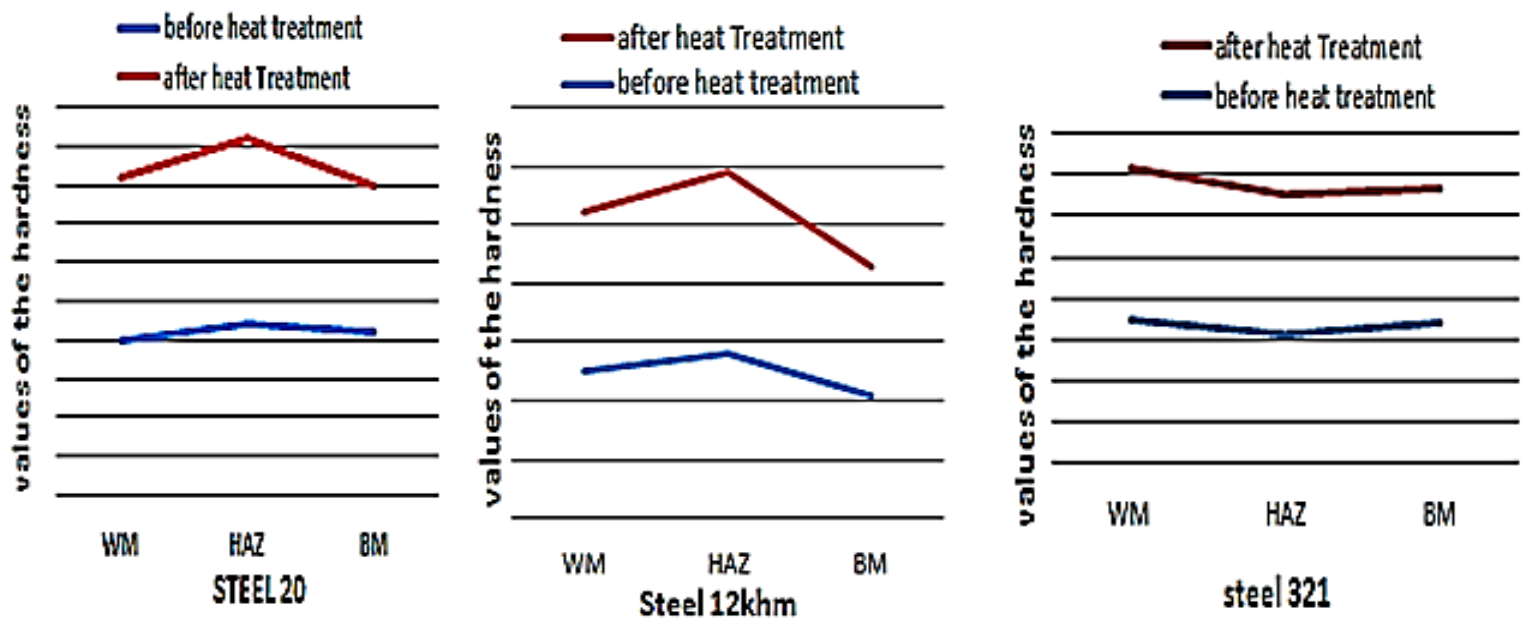

Figure 7: Hardness of welded joints in different zones at different conditions



Figure 8: The influence of Tensile strength on the parent metal and welded joints

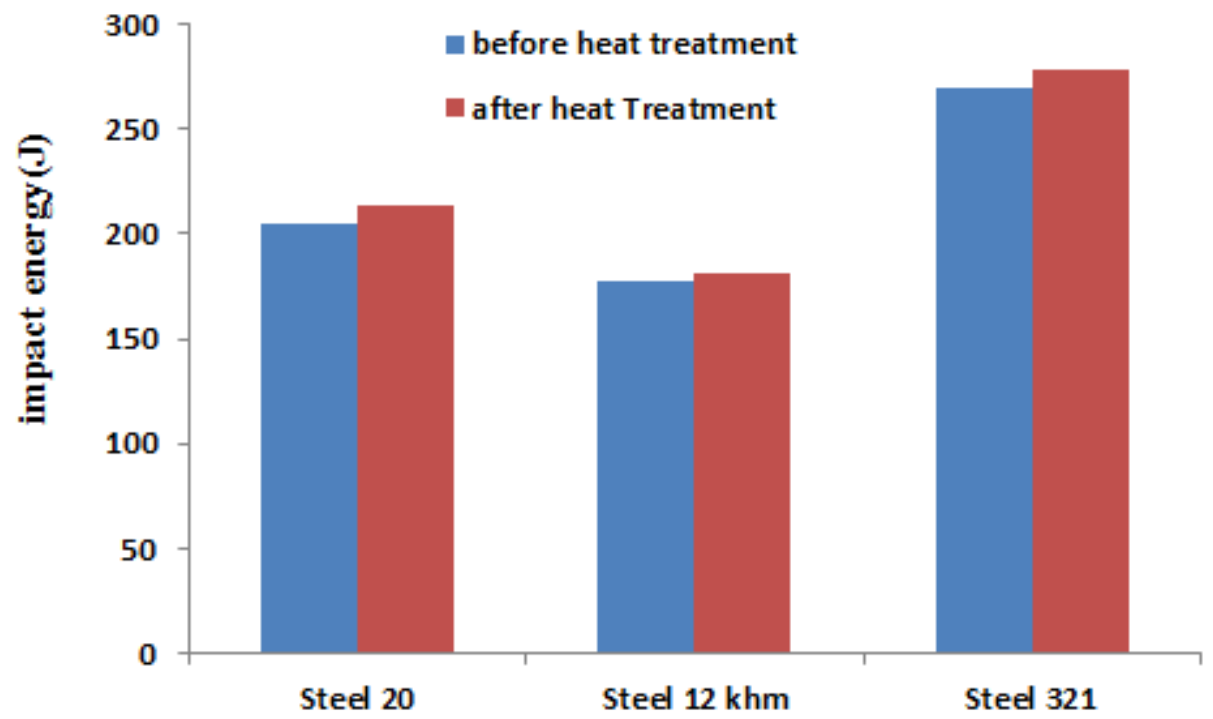


Figure 9: The influence of impact energy on the parent metal and welded joints

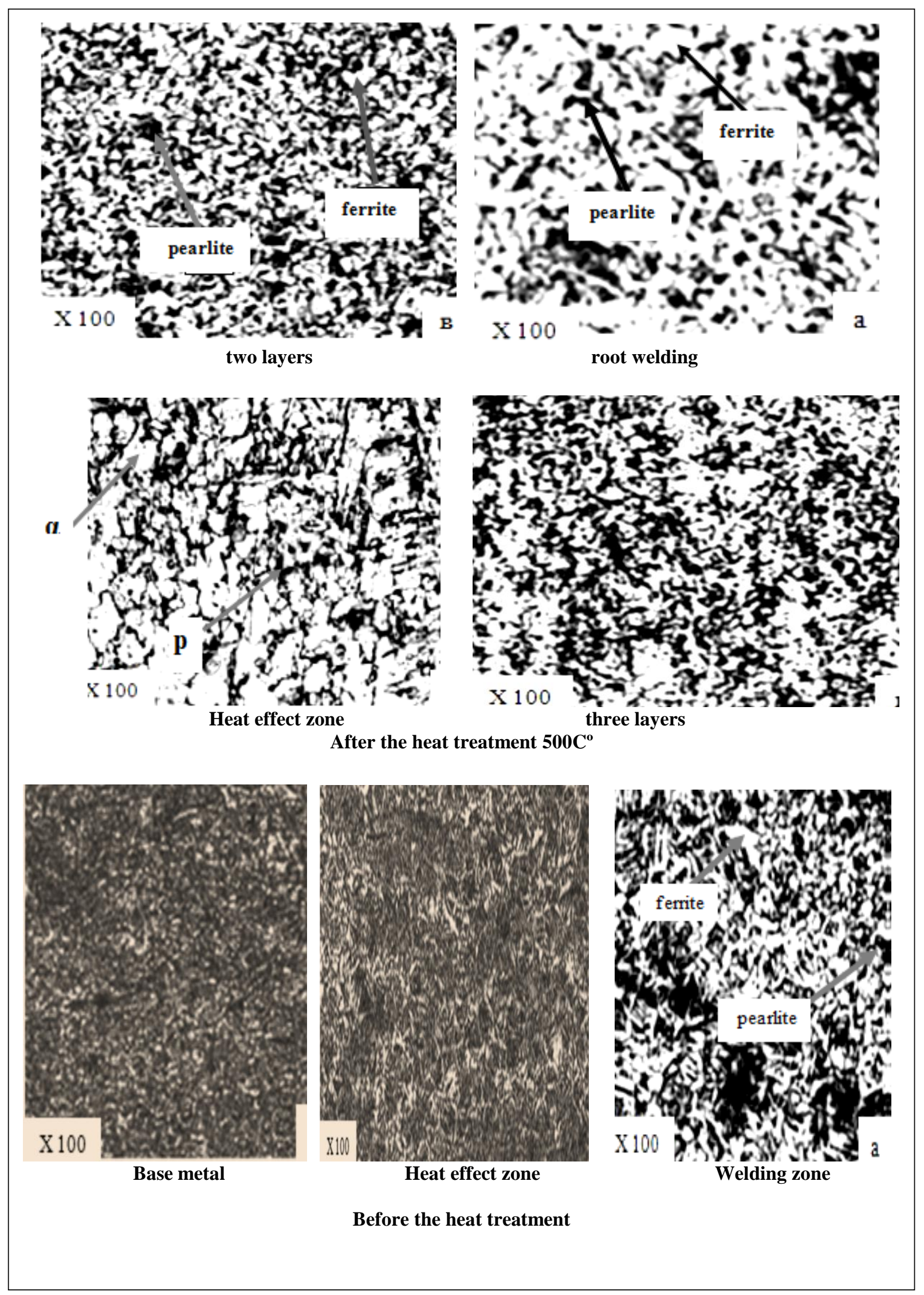

Figure 10 : Microstructural of steel 20 


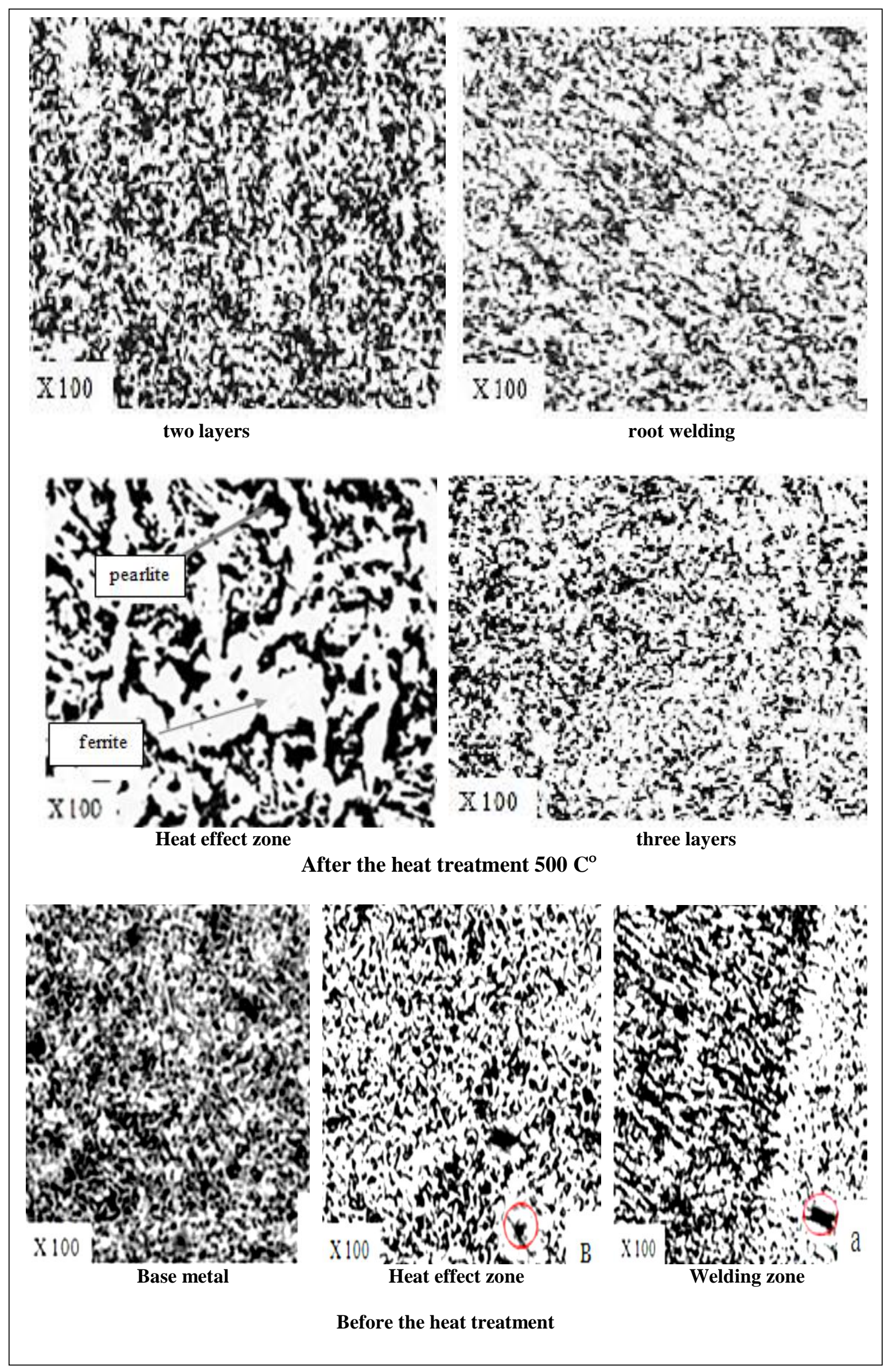


Figure 11: Microstructural of the steel 12KHM

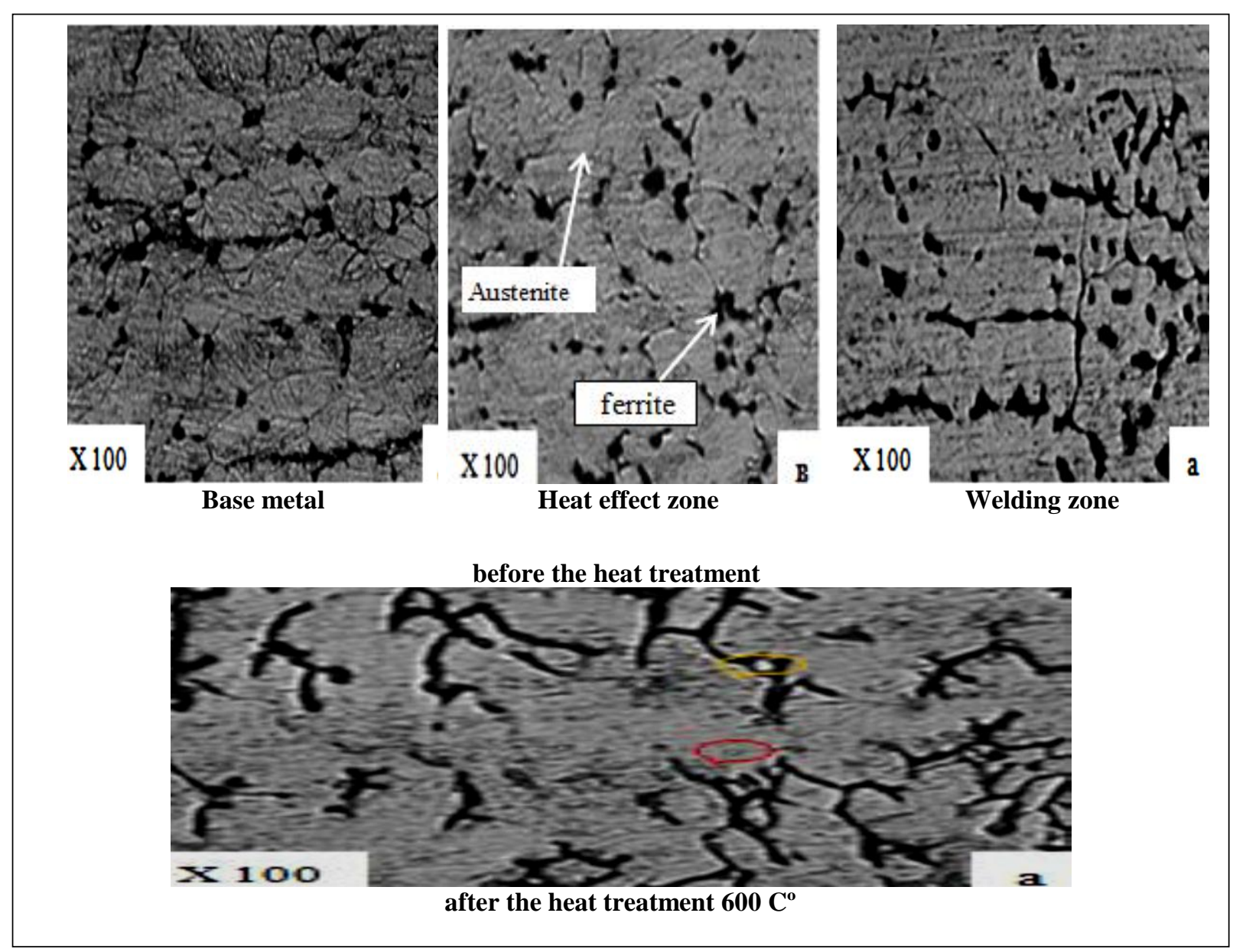

Figure 12: Microstructure of the steel 321 